\title{
NUCLEAR POWER WITHOUT THE PHOBIA
}

\section{David McMullen}

Melbourne

January 2007

Nuclear power presently generates about 16 per cent of the world's electricity, which constitutes about 6.5 per cent of commercially produced primary energy. ${ }^{1}$ All the major developed countries except Italy ${ }^{2}$, rely to a significant extent on nuclear power, ranging from 79 per cent in the case of France to around 20 per cent in the case of Japan, UK and US. It is also important in some of the former Soviet bloc countries. For example, the Ukraine receives 49 per cent and Russia 16 per cent. ${ }^{3}$ India and China also have some nuclear power.

The industry has its origins in the military programs of the USA and USSR in the 1940s and 50s which produced nuclear weapons and reactors to power naval ships and submarines. The technology is based on the fission process, which produces energy by splitting atoms. The fuel for the process is provided by uranium which is "enriched" to increase the proportion of the fissile isotope uranium-235. ${ }^{4}$

Presently there are 441 nuclear reactors generating electricity in 31 countries. ${ }^{5}$ These come in a number of varieties which are mainly distinguished by their system of transferring heat from the reactor to the power generator. All the reactors in the US and about 90 per cent worldwide are so-called light water

\footnotetext{
${ }^{1}$ IEA 2006a: 24 and 6. The primary energy equivalent of nuclear electricity is calculated by assuming a 33.3 per cent conversion efficiency from heat to electricity. See IEA 2006a: 59.

2 Italy imports from France electricity which is produced from nuclear power.

${ }^{3}$ http:/ /www.uic.com.au/reactors.htm

${ }^{4}$ Hore-Lacy 2000.

${ }^{5}$ http:/ / www.uic.com.au/reactors.htm. As well as commercial energy generation, there are about 280 small reactors, used for research and for producing isotopes for medicine and industry over 400 small reactors powering ships; mostly submarines. See Hore-Lacy 1999: v.
} 
reactors. ${ }^{6}$ Of these about two thirds use pressurized water while the rest use boiling water. Virtually all the remaining reactors are either a Soviet design using graphite or a Canadian one using heavy water.

After taking off in the 1960s and 1970s, the industry then sunk into a malaise. This can be attributed both to the increasing competitiveness of coal and gas power and to the emergence of a very unfavorable political climate marked by considerable public opposition and a switch in government policy from active encouragement to definite discouragement, including in some countries a decision to phase out the industry. This change of attitude received major boosts from the accidents at Three Mile Island in 1979 and Chernobyl in 1986 which highlighted the risks from radiation.

The industry is not entirely moribund. Improved methods have enabled existing plants to increase their total output and they are generally getting extensions to their licenses beyond their originally expected lifespan. There are presently 27 new plants under construction, including 8 in India, 5 in China and 4 in Russia, while another 38 are planned. ${ }^{7}$ A number of countries in Europe are dragging their feet on phase-out plans particularly in the context of reducing greenhouse gas emissions. The US administration is pursuing plans to encourage new construction during the second decade of the century, a policy that has bi-partisan support. Nevertheless, for the industry to maintain or improve its relative position it would need to undergo a major resurgence.

Nuclear power's competitive position may well improve in the future. Increases in fossil fuel prices could have a considerable impact on competitiveness given that fuel constitutes over half the life-cycle cost of a fossil powered plant. In contrast, prices of nuclear fuel have far less of an effect. While the doubling of uranium ore prices would increase nuclear generating cost by only 5 per cent, the doubling of natural gas prices would increase gas-fired generating costs by some 80 per cent. ${ }^{8}$

\footnotetext{
${ }^{6}$ NEA 2001: 15.

${ }^{7}$ http:/ / www.uic.com.au/reactors.htm

${ }^{8}$ NEA 2001: 138.
} 
Nuclear power would benefit greatly from anything that would reduce construction or capital costs. These typically account for 60 to 75 per cent of total generation costs, compared with 50 per cent for coal plants and 25 per cent or less for gasfired ones. ${ }^{9}$ There are a number of factors that could lead to a reduction in these costs. These include standardized large scale production, new plant designs and more rational safety regulation.

If nuclear power plants were built on a large scale various economies could come into play. First there are the economies that come with experience. Once a few plants have been built and commissioned, the experience gained will reduce the costs of future units..$^{10}$ Then there are the economies associated with specialized plant and machinery. Producing a large number of any product or component generally allows the investment in specialized production methods that would be too expensive at low production levels but would reduce costs at a larger scale of output. For example, you would not build a production line to produce a few hundred cars. It would be cheaper to make them 'by hand', i.e., with non-specialized machine tools. It is only when the number reaches a critical level that building a large specialized plant becomes cheaper, seriously cheaper. There are also a range of overhead costs, such as design and administration, that can be spread over a large number of units.

Standardization would also reduce the long delays due to the approval process that in the past have doubled the construction time and greatly increased the interest burden. According to new legislation being adopted in the US and elsewhere, once a standardized design has been certified as safe, all plants built to that design would automatically receive approval. Such prior approval could also be harmonized internationally in much the same way as in the aircraft industry. A power company would then only need to receive approval for the chosen site. However, even this may be unnecessary where the unit is to be built on an existing power plant site. Many sites have room for more reactors.

\footnotetext{
${ }^{9}$ IEA 2001b: 130.

${ }^{10}$ Cohen 1990:163-164.
} 
The new designs being considered for future reactors include various features that could possibly make them cheaper to produce. Many new generation nuclear plants including the Westinghouse AP-600 and 'pebble bed' would operate on 'passive' safety features which rely on natural forces such as gravity, convection, natural circulation, evaporation and condensation. ${ }^{11}$ In the case of the AP-600, this would mean 35 per cent fewer pumps, 50 per cent fewer valves, 70 per cent less cabling, and 80 per cent less ducting and piping than conventional LWR systems. ${ }^{12}$ According to the developers of the pebble bed reactor, their design has no need for an expensive containment shell to prevent the escape of radiation in the case of an accident. ${ }^{13}$ These and other new designs are also considered to be more suited to factory production and assembly of modules on site than the old generation of plants. ${ }^{14}$

The competitive position of the industry will be most favorable where transport infrastructure is inadequate or distances from fuel sources considerable because nuclear fuel is a fraction of the weight and volume of fossil fuel. This could tip the balance, for example, in India, northern China and western Russia. ${ }^{15}$

Nuclear power may benefit from a move towards a hydrogen economy. Electricity from existing nuclear power plants can be used for the electrolysis of water. Nuclear reactors could also provide the heat for the steam reforming of natural gas, the method that currently produces 95 per cent of hydrogen. Natural gas reacts with water at high temperature to form hydrogen and carbon dioxide. However, this would require a new generation of reactors that have a far higher coolant outlet temperature. An even higher temperature would be required for thermo-chemical water splitting which converts water into hydrogen and oxygen. While this technology is not yet commercially available, a number of steps are being taken in that

\footnotetext{
11 http://www.world-nuclear.org/info/inf08.htm; Hoffman 2001.

${ }^{12}$ Hoffman 2001.

13 Wardell 2001.

14 Abraham 2002: 5; Wardell 2001.

${ }^{15}$ Grimston and Beck 2000: 29.
} 
direction. A pilot project is being planned in Japan. The Americans and the French are also doing development work. ${ }^{16}$ Some breeder reactors would achieve temperatures suitable for these processes, as would the pebble bed reactors currently at the trial stage.

The resurgence of nuclear power would require an improvement in the political climate. If nuclear power begins to make economic sense where it did not before this could undercut opposition and strengthen support. The industry could also benefit from the fact that it does not emit greenhouse gases. This would depend on the extent that global warming fears cancel out radiation fears, and competition from other technologies with the same emission claims such as solar and wind.

For nuclear power to continue playing an important role in the second half of the century, there will need to be a large construction program. Just to maintain current output would require the replacement of existing capacity in coming decades. To maintain the current 16 per cent share in the face of the six fold increase in electricity generation that would be required to bring 10 billion people up to current per capita consumption levels of rich countries, there would need to be 2,646 reactors (441 x 5.3), assuming no change in average output. To produce all of this electricity there would need to be 16,537 of them $(2,646 / 0.16)$. This is one for every 605,000 people or somewhat more than the level for present-day France where there is one for every million people.

Nuclear power could conceivably meet all energy requirements of this population at the current OECD average, through the production of electricity, heat and hydrogen. To provide 10 billion people with the same annual per capita primary energy at current average rich-country levels, we need to produce 2,300 EJ (55,000 mtoe) a five fold increase. This would require 35,243 reactors, or seven for every two million people. ${ }^{17}$

16 UIC $2006 a$.

17441 reactors currently produce $28.78 \mathrm{EJ}$. (687 Mtoe) of energy (Electricity/ 0.0333). 


\section{Resources}

The current estimate of conventional resources of uranium is 14.4 million tonnes ${ }^{18}$ or over 200 years' supply at today's rate of usage of around 65,500 tonnes per year. ${ }^{19}$ A third of this is described as known conventional resources and would last almost 70 years at current usage rates while the remaining two thirds are undiscovered conventional resources, based mainly on estimates of uranium that is thought to exist in geologically favorable, yet unexplored areas. ${ }^{20}$ This figure is bound to considerably underestimate the ultimate resource. Investment in exploration has been quite low $^{21}$ and a number of countries, such as Australia with significant resource potential in sparsely explored areas, have not compiled figures for undiscovered conventional resources. ${ }^{22}$ Furthermore, according to Garwin this resource could be stretched by 25 per cent if more costly extraction methods were adopted that leave less of the uranium in the mining waste (tails). ${ }^{23}$

Thorium is another potential nuclear fuel, although currently not used. It is about three times more abundant in nature than uranium. ${ }^{24}$ Furthermore, all of the mined thorium is potentially useable, compared with the 0.7 per cent of natural uranium used in existing reactors, so some 40 times the amount of energy per unit mass might be available. ${ }^{25}$ The known resource is around 4.5 million tonnes. ${ }^{26}$ However, this is bound to be the tip of the iceberg given the limited extent of exploration and the fact that it does not include data from China, central and eastern Europe, and the former Soviet Union. Thorium processing and reactor technology still needs a lot of development before it could become commercialized. India which has more

\footnotetext{
18 NEA 2004: 13-22.

19 http://www.uic.com.au/reactors.htm

${ }^{20}$ NEA 2004:.20.

21 This was only $\$ 95$ million in 2002, NEA 2004: 9.

${ }^{22}$ NEA 2004:20.

${ }^{23}$ Garwin and Charpak 2001: 166.

24 NEA 2001: 30.

${ }^{25}$ UIC 2003.

${ }^{26}$ NEA 200422.
} 
thorium than uranium is in the forefront of research in this area.

There are also unconventional uranium resources to consider. These include about 22 million tonnes in phosphate deposits. ${ }^{27}$ The recovery technology is mature and has been utilized in the past; however, costs are somewhat higher than the present price. ${ }^{28}$ Then there is the 4 billion or so tonnes contained in seawater which could possibly become a resource. ${ }^{29} \mathrm{~A}$ number of trials have been performed to extract uranium and other valuable minerals from seawater. They use a special absorbent material and the cost at this stage is estimated to be around $\$ 300$ per kilogram. ${ }^{30}$ (At the time of writing the uranium spot price was $\$ 122$ per kilogram.) Another plausible method is to take advantage of the fact that life forms have the habit of taking up certain elements that are scarce in the nonliving world and concentrating them within their cells. For example, some sea animals accumulate elements like vanadium and iodine to concentrations a thousand or more times as great as in the surrounding sea water. It has been proposed that certain forms of algae could be cultivated to perform this trick with uranium..$^{31}$ No doubt seawater extraction would benefit greatly from a few decades of research and development.

When assessing the extent of nuclear fuel resources, it is important to keep in mind the possible adoption of so-called fast breeder reactors which extract around 60 times more energy from each kilogram of uranium. Conventional thermal reactors can only use uranium-235 which makes up less than one per cent of natural uranium. However, fast reactors, can harness most of the uranium which takes the form of uranium-238. They can also make very effective use of thorium.

There was considerable interest in this technology during the early years of nuclear power when it was thought that uranium

\footnotetext{
${ }^{27}$ NEA 2004: 22.

${ }^{28}$ NEA 2004: 22.

${ }^{29}$ NEA 2004: 22.

30 NEA 2004: 22.

${ }^{31} \mathrm{http}: / /$ users.rcn.com/jkimball.ma.ultranet/BiologyPages/E/

Elements.html
} 
would turn out to be scarcer and the industry a lot larger than proved to be the case. Around 20 plants were built in various countries including the US, France, the Soviet Union and Japan. ${ }^{32}$ Most of them were eventually closed due to high costs, teething problems including safety issues and declining support for the industry. However, there are now signs of renewed interest. India, China and Russia have reactors planned. Also, the Generation IV International Forum, representing governments from many of the nuclear power countries including US, UK, Japan and France, selected a number of fast breeder reactors to be among the six systems to be the focus for collaborative research and development. The objective is to make advances over existing systems in areas such as economy, safety, proliferation resistance and protection from attack and to have a number of systems available to be deployed by 2030.

So, to what extent could we rely on nuclear power? The current estimated resource of 14.4 million tonnes would only provide about 5 per cent ${ }^{33}$ of $21^{\text {st }}$ century energy production assuming 2 per cent annual growth and no increase in the energy obtained from each tonne. Furthermore, it would be used up by 2090 if the current share of 6.5 per cent were maintained or not much later than mid century if in a few decades time we pushed out capacity to a 20 per cent share.

However, it does not seem too wildly optimistic to envisage nuclear power being able to provide larger shares of this century's energy. Given more exploration and better extraction technologies the recoverable conventional resource could be considerably bigger than present estimates. Moderate increases in the energy harnessed from each tonne of uranium could also make a difference. Of course, the larger the share contemplated the more it would have to rely on the development of new technologies such as breeder or thorium reactors or the extraction of uranium from sea water. With such innovations the resource could become huge and a major provider of energy later this century or in the next.

32 Hore-lacy 1999: 39.

33 This follows from fact that the current 6.5 per cent share requires 65,000 tonnes of uranium. 


\section{The Safety of Nuclear Power}

Nuclear power is very much under a cloud because of distinctive safety issues relating to its fuel. It is highly radioactive and some of it can be used to make nuclear bombs. This prompts a number of fears: power plants emit small levels of radiation under normal operations and there is always the possibility of a major accident that releases large amounts of highly radioactive material into the environment as happened at Chernobyl in 1986; spent fuel may leak from its disposal site into the environment at some time in the future; and nuclear fuel may be diverted to terrorists for bomb making. The radiation concern is examined first and then the threat of nuclear terrorism where the principle hazard is the explosion rather than the radiation.

Radiation associated with nuclear power consists of subatomic particles that shoot through space at very high speeds. It is called ionizing radiation because it can penetrate our body, damaging cells in the process. In this way it is different from harmless forms of radiation such as radio waves.

Nuclear power reactors are not the only source of ionizing radiation. To begin with there is natural radiation to which humans always have been and always will be exposed. In the United States, people on average receive an annual dose of 300 millirems. ${ }^{34}$ This includes radiation from radioactive elements in rocks and soil, from within our own bodies and from outer space.

Radioactive elements in rocks and soil are principally potassium, uranium, and thorium. ${ }^{35}$ As well as naturally emerging from the ground, these can be released by human activities such as burning coal, oil, gas and wood, and by mining, plowing, construction and well-drilling. ${ }^{36}$ It means that brick, stone, and other building materials are slightly radioactive. Some types of building materials contain more radioactivity than others. For example, it has been claimed that Grand Central Station in New York City, which is a massive granite structure, provides commuters with a level of radiation exposure well in

\footnotetext{
34 Daley 1997: 60.

35 Cohen 1990: 183.

36 American Nuclear Society 2001: 7.
} 
excess of what they would receive from visiting a nuclear reactor. ${ }^{37}$ The radioactive material residing in our own body is from naturally occurring substances such as potassium 40 which are vital to our survival. These irradiate our organs including bone marrow, testicles and ovaries. We even irradiate each other at close quarters. This radiation from our bodies delivers an exposure close to a third of what we receive from rocks and soil. ${ }^{38}$ From outer space we receive cosmic radiation. Most of it is absorbed by the atmosphere, so we receive a higher than average dose by living at higher altitudes or by flying, mountain climbing or skiing.

As well as natural radiation, another big source of exposure is from medical radiology. This includes x-rays and a whole host of other diagnostic tools. In the US this source accounts for 35 per cent of all radiation exposure and 90 per cent of the total man-made dose. ${ }^{39}$ Other sources include TV sets, smoke detectors and airport X-ray machines.

Radiation exposure from all these various sources is fairly low. However, it is still far higher than routine emissions from the nuclear power industry. According to the United Nations Scientific Committee on the Effects of Atomic Radiation (UNSCEAR), estimated doses from nuclear facilities account for less than 0.05 per cent of the total dose from natural and medical sources. ${ }^{40}$

Even for those living near a reactor the exposure is a tiny fraction of what they receive from other sources. According to Cohen, it is comparable to what a typical viewer receives from a television picture tube. ${ }^{41}$

Radiation prompts two health concerns. At very high doses, of the kind that only the nuclear industry (civil or military) can deliver, it can cause radiation sickness which burns the skin and damages the central nervous system, internal organs and bone marrow. This damage allows rampant infection. Whether

\footnotetext{
${ }^{37}$ Sims 1990: 40-41.

${ }^{38}$ Garwin and Charpak 2001: 85.

39 Walker 2000: 48.

40 IEA 2001b: 171.

${ }^{41}$ Cohen 1990: 114,
} 
victims die or survive depend on the dosage, their health and age, and the quality of medical treatment.

The other health effect is an increased risk of cancer some time in the future, with the risk depending on the dose. In most cases the latency is 20 years or more. The exceptions are some childhood cancers and leukemia that may occur 3-5 years after exposure. ${ }^{42}$

There had in the past been concerns that radiation exposure could have genetic effects that could be passed on to future generations. However, the available evidence suggests that this is not the case. Research has shown that radiation can cause genetic mutation in plants and test animals including fruit flies. ${ }^{43}$ However, these have not yet been detected in people. Studies of the children of Hiroshima and Nagasaki atom bomb survivors show no excess of genetic defects. ${ }^{4}$ Nor is there any increased incidence in areas of high natural radiation. ${ }^{45}$ Radiation is presumably a weak mutagen for humans, just one of thousands of known mutagens in the environment which, combined, result in about 10 per cent of all new-born children showing some evidence of genetic defects. ${ }^{46}$ There is no evidence that radiation causes any other illness and this is in keeping with our knowledge of radiation and the causes of illness generally. ${ }^{47}$

The increased likelihood of contracting cancer depend on the level of radiation. The risk is known with a fair degree of certainty at higher levels of exposure. However, at the lower end there is far less certainty and quite a lot of controversy.

Given the extremely large number of people who contract cancer, it is difficult to determine statistically with epidemiological studies the extent to which radiation could be a contributor. In developed countries about half the population will get cancer from one cause or another and about half of

\footnotetext{
42 van der Zwaan: 20.

${ }^{43}$ Hore-lacy 1999: 59.

${ }^{44}$ Cohen 1982: 73; Walker 2000: 141; Hodgson 1999: 64.

${ }^{45}$ Sims 1990: 85.

${ }^{46}$ Sims 1990: 85.

${ }^{47}$ Cohen 1990: 69.
} 
those will die from it. This means that thousands of extra cancer cases in a particular population would cause a quite small increase in the rate and would be difficult to attribute to radiation rather than random variation in cancer rates or other factors that make this population different from others.

At the same token it is difficult to draw conclusions from unusually high or low cancer rates for small groups that have been exposed to higher than average levels of radiation. Small groups can be atypical for a range of reasons that are difficult to take into account.

At this stage our knowledge of how radiation does its nasty work is far too inadequate for us to assess its effect from first principles. More research has to be done into the nature of radiation induced cell damage and how it causes cancer.

In the past there was a general acceptance of what is referred to as the linear no threshold hypothesis (LNTH). This is based on a linear extrapolation from cases where high levels had been experienced and the risk level known with some degree of certainty. Most of the information is provided by studies of cancer incidence among those exposed to radiation from the atom bombs dropped on Hiroshima and Nagasaki. These survivors were exposed to an instantaneous dose of 100 s of rems plus subsequent longer-term exposure from fallout. Information has also been gained from the medical records of people subjected to heavy doses of X-rays as a treatment for spinal diseases, a misconceived practice that ceased in the early 1950s.

Based on these studies, scientists have estimated the cancer death risk from a radiation exposure of 100 rems to be 5 per cent. ${ }^{8}$ According to the LNTH, this can be extrapolated to much lower doses. So if a 100 rem exposure gives you a 5 per cent risk of developing a fatal cancer, a one rem (1000 millirem) exposure will give you a 0.05 per cent risk. In other words, halve the dose, halve the risk; double the dose double, the risk.

The LNTH also allows us to talk in terms of collective doses or 'person rems'. For every 2,000 person rems, there is one death. This can be achieved by a infinite number of combinations of dose and population. For example, one person

${ }^{48}$ Rutherford 2002b 
receiving 2,000 rems, 2,000 people each receiving one rem or 2 million people each receiving one millirem will all lead to one death. This is an effect that does not apply to most things we are exposed to and there is generally a threshold below which exposure is harmless. For example, 30 sleeping pills taken at once may be enough to kill an individual, however, that does not mean that if you take one tablet that you have a one in thirty chance of dying or if 30 people each take one that one of them will die.

The following examples should give a good idea of the kinds of risks implied by the LNTH. The background exposure of 300 mrem per year received by the US population of 300 million people would result in 45 thousand deaths per year. If we assume the same level of exposure for a world population of 6.5 billion people, this would result in 975,000 cancer deaths per year. As part of their background exposure, the average American receives about 31 mrems of radiation per year from cosmic rays. ${ }^{49}$ This would kill about 4,650 Americans per year. The levels of radiation naturally in our bodies is about 39 mrems. This translates into about 125,000 deaths annually worldwide.

It did not take long for a general dissatisfaction with LNTH to emerge. Most scientists think it overstates the risk. In other words a dose that is for example 50 per cent lower than another dose will have a more than 50 per cent lower cancer risk. Furthermore, below some level the cancer hazard is zero or so low that it is effectively zero. The general view among scientists is that there is a lack of conclusive evidence of low level radiation effects below total annual exposures of about 5 to 10 rems. ${ }^{50}$

It has been suggested that a threshold exists because up to a certain level our body has a capacity to repair a whole range of different kinds of damage. It is only when the attack reaches a certain intensity that the repair systems starts to be overwhelmed and the system is increasing degraded as the dose increases.

On the other hand a small number of researchers believe that

\footnotetext{
${ }^{49}$ Rutherford 2002a: 19

50 GAO 2000: 10.
} 
LNTH understates the risk for low level radiation. They supports the supra-linear hypothesis that more damage is caused per rem at low doses than at high doses. They theorize that perhaps low doses weaken and damage cells (which live on to damage other healthy cells), whereas high doses simply kill cells. ${ }^{51}$

While we need to keep in mind the problems with epidemiological studies, proponents of the prevailing view have a large amount of evidence which at least on the face of it supports their position. This includes the experience of Chernobyl, plant workers, medical patients, Japanese atomic bomb survivors who received relatively light exposure and the effect of differences in natural radiation levels.

In the case of survivors of the Hiroshima and Nagasaki bombings, those who received instantaneous radiation doses of less than 20 rems have not suffered increased cancer rates. ${ }^{52}$

A UN study 14 years after the Chernobyl accident concluded that up to then, there have been no increase in deaths from leukemia even among recovery workers who received fairly high doses of radiation, despite its latency period of only 5-10 years after radiation exposure. ${ }^{53}$

Extensive studies by radiation protection bodies have been unable to detect any sign that workers dealing with radioactive material have cancer mortality rates which are higher than those for the general population. ${ }^{54}$ A study of over 20,000 men who took part in the UK atomic bomb tests in Australia and the Pacific in the 1950s showed no detectable effect on their life expectancy or on the incidence of cancer or other fatal diseases. ${ }^{55}$ A study of the mortality rate among 30,000 persons exposed to radiation while working with nuclear ship propulsion systems was lower than the mortality rate among another 30,000 persons in a control group who received a more normal

\footnotetext{
${ }^{51}$ Kaku and Trainer 1982: 29.

52 Cohen 1998:525.

${ }^{53}$ Chernobyl Forum 2003-2005: 7.

${ }^{54}$ Hodgson 1999: 68

${ }^{55}$ Hodgson 1999: 68.
} 
amount of radiation per year. ${ }^{56}$

There is no sign that regions with higher levels of natural radiation have higher cancer rates. These are at a higher altitude and more exposed to cosmic rays and/or have higher than normal uranium content in their soil. The cancer death rate in seven western states in the US is 15 per cent lower than in the rest of the continental US even though the level of radiation is almost twice as high. ${ }^{57}$ In some parts of India and Brazil the natural background is over ten times the world average, due to the presence of radioactive rocks, but the population shows no signs of being affected. ${ }^{58}$

It is even possible that small radiation doses are beneficial. An explanation offered for this is that low radiation stimulates the body's repair mechanisms. ${ }^{59}$ Experiments indicate that the irradiation of mice by gamma rays increases their survival rate by one week per rem, and that the irradiation of salmon eggs increased the number of viable eggs and the rate of return of the adult fish to their birthplace to breed. ${ }^{60}$ There are also statistical studies of human exposure that support this proposition. Twenty years ago in Taiwan, recycled steel, accidentally contaminated with radioactive cobalt-60, was used in the construction of more than 180 buildings which were occupied by about 10,000 people for between 9 and 20 years. ${ }^{61}$ With seven cancer deaths, the cancer mortality rate for this population was 3.5 per 100,000 person-years compared with the rate in the general population of Taiwan over these 20 years of 116 persons per 100,000 person-years. Assuming that the people concerned were fairly typical of the population at large in terms of factors such as income and age - and this needs to be confirmed - the experience of these people seems to suggest that long-term exposure to radiation, at a dose rate of the order of 5 rem per year, greatly reduces cancer mortality. This is more

\footnotetext{
56 Oliver 2001.

${ }^{57}$ Kursunoglu 1998: 39.

${ }^{58}$ Hodgson 1999: 63-65.

59 American Nuclear Society 2001: 7.

${ }^{60}$ Hodgson 1999: 65.

${ }^{61}$ Chen 2004.
} 
than 10 times what people are presently receiving. ${ }^{62}$

\section{Plant Safety}

Normal Operations

During the normal operation of a nuclear power plant, gaseous and liquid discharges containing very low amounts of radioactive material are released into the environment. The extent of these emissions (both absolutely and per unit of generated electricity) has been reduced considerably since the early days of the industry by the use of improved technology, and this is continuing. ${ }^{63}$

Government regulations place limits on these emissions which keep exposure to a minute fraction of the natural background radiation levels that people already experience. In many countries permissible levels are set so that a hypothetical person who stood at the boundary fence, drank the plants cooling water and consumed food grown nearby, would not receive more than some minute increase in their normal exposure level. ${ }^{64}$

In reality, of course, no one experiences even that minute increase. No one lives at the reactor fence and even if they did they would not experience the maximum exposure because most plants keep their emissions well below this level. ${ }^{65}$ The average lifetime exposure for people living in the nuclear power regions such as North American and Europe is next to nothing and less than the increased natural radiation exposure from a long plane trip. ${ }^{66}$ On an annual basis, people living near to a nuclear power plant receive about 1 mrem of extra radiation exposure. ${ }^{67}$

Studies of populations surrounding nuclear reactors also suggest no health effects. A US survey sponsored by the

$62300 \mathrm{mrem}$ in the US.

${ }^{63}$ van der Zwaan. et al. 1999: 259; Cohen 1990: 205.

${ }^{64}$ Walker 2000: 52; Sims 1990: 40.

65 Walker 2000: 31; Sims 1990: 40.

${ }^{66}$ Sims 1990: 243. Walker 2000: 117.

${ }^{67}$ Cohen 1990: 54. 
National Cancer Institute studied cancer deaths in 107 counties with nuclear facilities within or adjacent to their boundaries. ${ }^{68}$ Each county was compared to three similar 'control counties.' Their report, published in 1990, found 'no evidence to suggest that the occurrence of leukemia or any other form of cancer was generally higher in the study counties than in the control counties.' Studies in other countries generally supported the NCI's findings, including ones in France and Canada. ${ }^{69}$

\section{Reactor Accidents}

A much bigger concern than routine emissions is the threat of reactor accidents that release large amounts of radioactive material into the environment and endanger the health of thousands.

Any serious accident would have to be the result of a string of mishaps. In the first instance there would have to be a breakdown in the cooling system which leads to the melting of the reactor core - a "meltdown". This in turn would have to cause an explosion which spreads radioactive material into the environment.

Fortunately the risk of such accidents occurring is quite low. This is really most clearly in the truly remarkable safety record for nuclear reactors over the past half century. In the case of the water reactors used in most of the world's nuclear power plants, there has been over 12,000 reactor years of service without an accident endangering the public. There has also been a similar amount of service by research and marine reactors with an equally unblemished record. The US navy alone has accumulated more than 5500 reactor years of operational experience with its nuclear submarines, icebreakers and aircraft carriers.

There has been one serious accident and that was at Chernobyl in the Ukraine in 1986 during a misconceived experiment. However, that said more about the state of the Soviet Union in its dying days than it does about the safety of nuclear reactors. The accident would not have happened but for a string of procedure violations. According to the Soviet investigators, there

\footnotetext{
68 Walker 2000: 139.

${ }^{69}$ Walker 2000: 139.
} 
had been six separate contraventions of procedures by the reactor operators during the experiment. If any one of these had not been committed, the accident would not have happened. ${ }^{70}$ There was a strong culture of disregarding safety rules and a complacency encouraged by the fact that past accidents and mishaps were kept secret from those in the industry as well as the public at large. This was reflected in the fact that an electrical engineer with limited knowledge of reactor operations was in charge of the "experiment," and there was no one in the control room who understood the risks they were taking. Furthermore, the Chernobyl reactor was of a Soviet design that was far more vulnerable to criminal negligence and incompetence than types used elsewhere. The reactor had graphite as a moderator instead of water, so that the loss of water coolant can increase the chain reaction and resulting heat, whereas with a light water reactor loss of coolants brings the chain reaction to a halt and limits the heat that can be reached by the reactor core. Also, the reactor did not have the massive containment structure common to most nuclear plants elsewhere in the world. According to some analysts, this would have withstood the steam pressure that caused the explosion.

Generally speaking a disaster in a reactor is remote because of a range of emergency safety features and the need for a number of unlikely and unrelated mishaps. Of particular importance are the back up arrangements for the cooling system which prevents the reactor core from overheating. There are backup pumps and massive flywheels that keep water circulating even if the power is cut. If the main cooling system fails, emergency core-cooling systems which are independent of the primary core-cooling system come into operation. In some cases this system is a pressurized water tank that does not need pumps but simply dumps large amounts of water on the reactor. It is very unlikely that both the primary core and emergency core cooling systems would fail.

The rods that control the chain reaction also have a number of emergency features. Firstly there is a number of independent clusters of control rods that can be inserted by gravity into the

70 Sims 1990: 108. 
core to stop the reaction. Any one of the clusters would be enough to achieve this. ${ }^{71}$ In the case of a power failure, the control rods are immediately released because they are only held above the reactor by electromagnets. ${ }^{72}$

If there is damage to the reactor core as a result of a failure in the cooling system what happens then? In the first instance, radioactive fuel has to escape from the steel pressure vessel into the containment dome and then set off a steam or hydrogen explosion that breaches the dome encasing the reactor. This would have to be quite a powerful explosion given that the dome is made of steel-reinforced concrete about a meter thick.

Experiments suggests that it is not easy to set off a steam explosion. For example, in 1980 scientists at the Sandia Laboratory in New Mexico unsuccessfully attempted to create a large one by dropping molten uranium into water. ${ }^{73}$ Nevertheless, the inside of the protective dome is equipped with water spray nozzles or refrigeration systems that will condense the steam and reduce the pressure. ${ }^{74}$ Some reactors have large volumes of ice on hand. ${ }^{75}$

The concern about hydrogen stems from the fact that it may be released by a chemical reaction if extremely hot steam comes in contact the fuel-casing material. ${ }^{76}$ However, according to Cohen, the research seems to indicate that even if all the hydrogen that could possibly be generated by core damage were to explode all at once, the force would not be powerful enough to break most containments. ${ }^{77}$ In nearly all scenarios the hydrogen would be produced gradually and ignited in a series of small explosions or fires caused by sparks from various sources such as electric motors. This is assisted in some cases by the installation of devices that constantly create sparks. Some reactors have an inert gas in the containment so depriving any

\footnotetext{
${ }^{71}$ Garwin and Charpak 2001: 171-172.

72 Hodgson 1999: 79.

${ }^{73}$ Kaku and Trainer 1982: 82-83.

${ }^{74}$ Nero 1982: 87-88.

${ }^{75}$ Cohen 1990: 86-89.

${ }^{76}$ Cohen 1990: 80.

${ }^{77}$ Cohen 1990: 86-89
} 
hydrogen of the oxygen needed for an explosion.

If the dome can hold out for a few hours from the initial release of radioactive material, a lot of it will either become stuck to the dome walls or equipment, or be removed by various systems in place for that purpose. The latter includes ventilation systems and water sprinklers for removing particles from the air. ${ }^{78}$

As well as the prospect of reactors exploding radioactive material into the air and surrounding landscape, there is also a concern about groundwater contamination if the fuel melts through the thick concrete floor. This has been colorfully dubbed the 'China syndrome'. However, according to Cohen, if molten fuel were to come into contact with groundwater it would flash into steam which would build up sufficient

pressure to keep the rest of the groundwater away. ${ }^{79}$ Once the fuel cooled it would be in the form of a glassy insoluble mass. If there were a problem, measures could be taken in good time to prevent any ongoing contact.

Various studies suggest that nuclear facilities would withstand external impacts such as World Trade Center style attacks. An aircraft may look quite solid but it is actually fairly light and flimsy. Given the small size of the protective dome the worst that could happen is to be hit by one of the engines. Studies also show that spent fuel storage pools are also able to withstand such attacks and experimental evidence proves that dry storage and transport casks would retain their integrity. ${ }^{80}$

Earthquakes are another concern. In the popular imagination there are visions of plants splitting in two or being swallowed up by cracks in the earth. The reality is very different. Like many modern structures, nuclear power plants in or near earthquake prone regions are built to withstand the worst expected earthquakes. They also have equipment that monitors seismic activity constantly and would be shut down in the event of an earthquake. ${ }^{81}$

\footnotetext{
78 Cohen 1990: 77.

79 Cohen 1990: 86-89.

${ }^{80}$ UIC 2006b.

81 http://www.uic.com.au/nip20.htm
} 
The Three Mile Island (TMI) semi-meltdown is the only serious incident involving a water reactor. However, there was no loss of life nor significant radiation emissions that could cause future health problems. Nevertheless, it was still a major mishap because the facility was completely disabled, and some argue that it could have easily turned into something a lot worse. Furthermore, it gained added significance from the fact that it was perceived to be a lot worse than it really was and contributed to a growing opposition to nuclear power.

Investigations revealed that the problems were mainly in the way the plant was operated rather than in the technology. ${ }^{82}$ This has generally lead to better training, improved controls and instrumentation and practices such as always having an engineer on duty. By closing off the TMI route to meltdown, these measure have made reactor operations safer.

Serious technological and management failings cannot of course be ruled out. This is exemplified by the recent incident at the Davis-Besse plant in Ohio, US where the pressure vessel had been badly corroded by the boric acid in the cooling water. This represented both a technological chink in the armor given that it arose from an unanticipated problem and a management failure in that a flawed inspection regime failed to pick it up. The Nuclear Regulation Commission deemed it to be a serious incident in that it involved a serious loss of defense in depth capability. According to the Commission, a worst-case failure scenario would have been a high-pressure leak of slightly radioactive primary cooling water (as steam) into the reactor containment building. The plant operators have replaced local management and spent large amounts of money on repairs and improvements. Other plants have been inspected to check for similar structural degradation but nothing has been found.

What about the increased risk from a growth in the number of reactors, in the event of a resurgence of the industry? What may seem like a low risk when there are only 441 reactors, may be looked at differently when there are thousands of them. This concern should be allayed by the fact that future reactors will be even safer than present ones. There will be greater reliance

82 UIC 2006b. 
on safety systems that employ perfectly reliable 'passive' natural forces such as gravity, natural circulation, convection, evaporation, and condensation. ${ }^{83}$ In the case of the pebble bed design, each fuel pebble is surrounded with its own outer shell that traps all radioactivity inside and if the helium coolant completely leaked out of the core, the fuel would not get hot enough to melt the uranium oxide within the fuel pebbles. ${ }^{84}$

The next question is - if a reactor blows how likely is it to lead to some incomparable disaster rather than one of more normal proportions? Certainly to achieve the more disastrous outcomes require less likely events or combinations of events. We need a failure by emergency workers to stem the emissions. This could be followed by evacuations being blocked by floods or snow storms. The situation could then be made even worse by an atmospheric temperature inversion concentrating radioactive material over a large trapped population down wind of the reactor. While we can conjure up such mega-death scenarios, they should not necessarily influence our actions if they are no more likely than other risks of disaster that are an inevitable part of life and of doing the things we want to do. For example, the government does not prohibit major sporting events because of the minute risk that the stadium will collapse from a construction fault or be hit by a falling Boeing 747 .

What can Chernobyl tell us about the possible impact of a nuclear reactor disaster? According to the 2000 report by the UNSCEAR, there were 134 confirmed cases of radiation sickness among reactor and emergency workers who were on the scene at the time of the accident and received very high radiation doses. Of these 29 died within four months of the accident. A further 11 died between 1987 and 1998. The survivors from this group have a range of illnesses and a raised risk of cancer in future years.

Among the 240,000 recovery workers exposed to fairly high doses in the initial cleanup phase, there has to date been no raised cancer rate. This is surprising in the case of leukemia which usually emerges within a few years of high radiation

\footnotetext{
83 Hoffman 2001.

84 Wardell 2001.
} 
exposure and gives weight to the anti-LNTH position. On the other hand, there is still the prospect of a raised rate for other cancers in the future given that it takes 20 years or more for radiation to have its effect. With the doses received by this group, and assuming LNTH, we can expect to see a thousand or so extra cancer deaths in the future. Among the few hundred thousand recovery workers who arrived more than a year after the accident, the radiation dose was much lower and any increase in cancer deaths would not be high enough to be detected in any epidemiological study.

Beyond the reactor site and its immediate surrounds, radioactive contamination mostly affected an area of $150,000 \mathrm{~km}^{2}$ with a population of about five million people. However, the only public health impact of radiation within this area that is in evidence 20 years after the accident are 1800 mostly treatable cases of thyroid cancer due to childhood exposure to radioactive iodine. The thyroid gland of young children is particularly susceptible to the uptake of radioactive iodine which has a halflife of 8 days and was a major component of the fission products released from the reactor. Indeed, many of these cases could have been avoided. A low iodine diet made the children more susceptible. Also the authorities could have been more effective in their distribution of stable iodine to prevent the uptake of radioiodine by the thyroid and in restricting the consumption of milk and fresh leafy vegetables in the vicinity of Chernobyl. People who were children at the time of the accident continue to have an increased risk of thyroid cancer, especially those who were under five years old. In the case of other cancers, no statistically noticeable rise in death rates is expected in the future because of the low radiation dose received.

As we can see this is a tale of human tragedy and hardship but it is not Armageddon. If anything in this sorry business is in line for that title it is the psychological and medical trauma caused by the gross over-reaction to the accident. Hundreds of thousands of people have had their lives disrupted by being relocated from regions where the radiation level had been raised to levels that were still less than the natural level in many parts of the world. This has lead to high rates of unem- 
ployment, depression, hypochondria and stress-related illnesses such as heart disease and obesity. Then there is a grossly exaggerated fear of getting cancer which is way out of proportion to what is actually a fairly small risk. Anti-nuclear fear mongering must take some of the blame for this state of affairs.

So, where in the spectrum of nuclear accidents does Chernobyl belong? It was certainly a very bad accident. The roof was blown off and large quantities of radioactive material were scattered over the surrounding region. One can imagine how it could easily have been worse. For example, the reactor could have been in a more heavily populated location and the weather crueler in where it delivered rain from radiation filled clouds.

However, these factors would appear to be overshadowed by the range of ways that it could have turned out a lot better if it had not been for the circumstances particular to the Soviet Union. To begin with the reactor was a type that used graphite as a moderator rather than water. This type is not used in the West. Burning graphite proved to be an excellent means of distributing radioactive material into the atmosphere. Emergency workers were poorly protected by western standards and the performance of emergency measures was not always "best practice". Evacuations were delayed because the authorities did not want to admit to a serious accident until absolutely necessary.

However, even if there were a good chance of an accident turning out worse than Chernobyl, it would have to be a lot worse to be a disaster of unusual proportions. Events worse than Chernobyl on a fairly regular basis would probably compare favorably with the deaths from coal mining and fossil fuel emissions or from motor vehicle accidents. Possibly, the deaths from Chernobyl will turn out to be less than what would result from installing millions of wind turbines or solar panels.

\section{Nuclear Waste}

A common arguments against nuclear power is that there is a "waste problem." It is claimed that we are unable to safely dispose of the radioactive waste created both in mining and 
uranium processing, and in reactor operations.

Mining and Uranium Processing Waste

The main form of radioactive waste from the 'backend' of the process is the ore body after the removal of the uranium. This is called tailings and there is about 400 tonnes of if for every tonne of uranium ${ }^{85}$ and it is 50 to 100 times more voluminous than all other radioactive wastes combined. 86

Its radioactivity is similar to that of natural uranium, however it potentially constitutes more of a hazard because it is on the earth's surface rather than in the ground and in a pulverized form. It generates radon gas and radioactive particles that can get into the air or contaminate streams. However, emissions from uranium tailings would still only be a mere fraction of natural emissions from the soil and considerably less than that released by tillage of the soil by farmers. ${ }^{87}$

Tailings emerge from the uranium milling process dissolved or suspended in water. This liquid is pumped into ponds or dams which have to meet certain design specifications to prevent contaminating the ground underneath. The process water is then decanted into a settling pond while the remaining tailings dry out leaving what looks like piles of sand. This is covered over with enough rock, clay and soil to reduce radiation to levels naturally occurring in the region and then a vegetation cover is established. ${ }^{88}$

Various processes are employed to remove chemicals and radioisotopes from the decanted water. These are retained as a sludge that settles on the bottom of the pond. The water evaporates or is released according to stringent rules on radiation and other contaminant levels. The sludge is collected and disposed of when the site is decommissioned. ${ }^{89}$

There are some problems with mine and mill waste from a time when procedures were less strict. These still require efforts

\footnotetext{
85 IEA 2001b: 175.

86 IEA 2001b: 197.

87 Sims 1990: 175.

88 Hore-Lacy 1999: 32.

89 Sims 1990: 164.
} 
to stabilize, protect or relocate the waste..$^{90}$ Past mining practices were also a hazard to miners, with high radon exposure leading to higher incidence of lung cancer. However, this has not been a feature of uranium mining for some decades. ${ }^{91}$

\section{Reactor Waste}

The other form of waste results from reactor operations - 'front end' waste. It is a much smaller quantity, however, it includes medium and high level waste.

In terms of volume most of it is low level waste that decays fairly quickly, with most of it fading to background levels within months or years. ${ }^{92}$ This waste includes filters and the radioactive material that they have collected from air and water in the reactor, and things that have been contaminated by contact with radioactive material, for example, gloves, clothing, pipes and valves. Not all of the low-level radioactive waste is from the nuclear industry. A significant proportion is from other users of radioactive material such as hospitals and research laboratories.

Intermediate-level wastes include chemical processing resins, fuel rod casings and metal from spent fuel assemblies ${ }^{93}$ and makes up less than 20 per cent of reactor waste by volume. ${ }^{94}$

While only comprising 5 per cent of the total volume, high level waste contributes 95 per cent of the radioactivity. This is the spent fuel from the fission process. The entire US nuclear power industry produces about 2,000 tonnes annually ${ }^{95}$ and has produced about 50,000 tonnes since the industry began. ${ }^{96}$ This is equivalent in weight to a medium sized cruise ship.

\footnotetext{
${ }^{90}$ IEA 2001b: 197.

${ }^{91}$ Hore-Lacy 1999: 56.

92 Holt 2003: CRS-5.

${ }^{93}$ IEA 2001b: 195.

${ }^{94}$ Hodgson 1999: 70-2.

${ }^{95}$ Holt 2003: CRS-6.

${ }^{96}$ Holt 2003: CRS-6.
} 
Storage or Disposal of Waste

\section{Current Arrangements}

Presently most high level waste is kept in temporary storage facilities at the plant site. It is placed in specially designed containers and stored in pools of water that keep it cool and prevent radiation emissions. In those countries with fuel reprocessing plants, their high level liquid wastes are stored in cooled multiple-walled stainless steel tanks surrounded by reinforced concrete. ${ }^{97}$ In both cases temporary storage is designed to do its job for many decades to come. Most intermediate waste is also kept in temporary storage..$^{98}$

Low-level waste is typically stored on-site, either until it has decayed away and can be disposed of as ordinary trash, or until amounts are large enough for shipment to a low-level waste disposal site in special containers. ${ }^{99}$ The waste is typically packaged in steel drums and buried in shallow trenches at licensed burial grounds. ${ }^{100}$ Some countries use engineered facilities such as concrete lined trenches or vaults and there is some move towards deep disposal. ${ }^{101}$

\section{Permanent Disposal}

Temporary storage of high level waste has proven quite effective and is designed to last indefinitely. Furthermore, it would be easier to dispose of a few decades down the track, when the heat and radioactivity has dropped to a small fraction of the level when it was first removed from the reactor.

The view that we need permanent and inaccessible storage that requires no action by future generations seems to be based on the following two premises. Firstly, the waste is a burden we should not pass on to future generations. We enjoyed the benefits so we should bear all the costs. Secondly, future generations may regress to Mad Max barbarism or 'advance' to a

\footnotetext{
${ }^{97}$ Hore-Lacy 1999: 46.

98 IEA 2001b: 196.

${ }^{99} \mathrm{http}: / /$ www.nrc.gov/waste/low-level-waste.html

100 Cohen 1990: 206.

101 IEA 2001b: 196.
} 
low tech utopia of 'simple living' and be incapable of dealing with the waste. (By the way, it is easy to imagine how the latter could quickly degenerate into the former.)

The first premise fails to recognize the huge debt that our descendents will owe us for the their inheritance of accumulated capital, and technical and scientific knowledge. Looking after some ancestral waste is a small recompense. Furthermore, any burden will be greatly reduced by the onward march of science and technology which will provide increasingly cheaper methods of storage or disposal.

It is hard to worry about the second premise. If we revert to barbarism or feudalism, radiation exposure in some areas would be a small problem compared with all the other sources of increased death and misery accompanying this new state of affairs. Furthermore, at least in the case of medium and low radiation doses, there would be less impact in a society that has regressed to a life expectancy of 35 years or so. Most people would have died of something else before any increased risk of cancer had had time to kick in. And in the case of high doses, people would soon learn to stay away from its source and incorporate it into their myths and legends.

Also, by not going down the inaccessible permanent disposal route, we would be retaining what may turn out to be a valuable resource if available for use in future reactors that make full use of the uranium and not just uranium-235. Another argument for continued accessibility which should appeal to the worriers is that it would allow future generations to make disposal super super super safe and not just super super safe:

The ability to monitor and gain access to waste once it is in a permanent disposal site is seen as increasingly important to public acceptance of disposal plans. This would allow future generations to determine whether the site is still safe. Maintaining some access to the site could be useful for two reasons related to public acceptance. First, it would make it easier to correct problems if they arise. Second, it would allow future generations to apply new methods of waste disposal. ${ }^{102}$

Despite the strong case against it, inaccessible permanent disposal is the policy in ascendance. Given this, ocean dumping should be the preferred method because it is cheap as well as 
safe. The waste would simply have to be converted into an insoluble form and placed in containers designed to last for thousands of years. In the unlikely event of a canister failing, any radiation would be released slowly and be diluted in the ocean where it would be scarcely noticed given that the ocean already contains 4 billion tonnes of uranium and other radioactive elements. ${ }^{103}$ Besides, ocean dumping is done by nature all the time. Uranium ore is continually being eroded into rivers and finally discharged into the sea.

Even cases of accidental or rogue dumping indicate that concerns are overblown. Russia has dumped sixteen complete nuclear reactors from old submarines and ships into the Kara Sea north of Siberia. Six of them still contained spent fuel. These were not encased in concrete or carefully buried in the ocean floor. They were just dumped. However, despite this rather insouciant manner of disposal, researchers have been unable to detect any measurable radiation from these reactors anywhere in this fairly small area of water. ${ }^{104}$ Over time they will be buried by the silt which is delivered in great quantities by the Yenisey River. In 1968 a US B52 bomber armed with plutonium fueled nuclear bombs crashed off the coast of Greenland. The recovery team were only able to retrieve around 90 per cent of the plutonium with the rest dispersed into the shallow coastal waters. Subsequent research indicated no increase in plutonium concentrations suggesting that it had been encased by the sediments on the sea floor. Seven nuclear submarines are currently sitting safely on the sea floor. One of the them, the Soviet submarine K-8, it is feared left 20 nuclear mines at the bottom of the Gulf of Naples before sinking under tow in the Bay of Biscay. The Soviet wreck which sunk in 1989 did, however, require 'repair' work to prevent radiation leaks. Of course, as things stand ocean disposal is politically impossible because it pushes all the phobia buttons and is now even prohibited under the London Dumping Convention. This leaves geological disposal.

A number of countries have identified potential under-

103 Hodgson 1999: 73.

104 http:/ / www-ns.iaea.org/appraisals/west-kara.htm 
ground storage sites and have conducted geological and geophysical tests to determine their suitability. These include Belgium, Canada, Finland, France, Germany, Spain, Sweden, Switzerland and the United States. Possibly the first cab off the rank will be America's site at Yukka Mountain in Nevada, although when it will finally open is still unclear. Compared with ocean disposal this method is appallingly expensive, although not prohibitively so given that it still would be only a couple of percent of the cost of nuclear power.

The primary safety concern with underground storage is that the waste would eventually be dissolved by ground water and carried by it into wells, rivers, and soil. This could then get into human stomachs through drinking water supplies or through food plants that have picked up contaminated water in the roots. ${ }^{105}$ The chance of exposure through inhaling contaminated dust is far less because groundwater only occasionally breaks the surface and 95 per cent of the dust we inhale is filtered out by hairs in the nose, pharynx, trachea, and bronchi and removed by mucous flow. ${ }^{106}$ Direct irradiation by radioactive materials in the ground would not be a problem because rock and soil are excellent shielding materials that radiation cannot penetrate. ${ }^{107}$ Other concerns relate to possible disturbances such as earthquakes, erosion, volcanic activities, mining and meteor impact.

Geological disposal is based on the strategy of multiple barriers, working from the innermost to the outermost. Firstly, the waste is in a form, possibly glass, that is not readily dissolved. Both archaeological and experimental evidence suggests that dissolving glass is an impossible task. ${ }^{108}$ Secondly, the waste is sealed in corrosion-resistant containers. In the case of Yukka Mountain, these will have an outer layer of titanium. Tests have shown that this metal would prevent water penetration for thousands of years when immersed in a very hot and abnormally corrosive solution, while under more normal groundwater

\footnotetext{
105 Cohen 1990: 179.

106 Cohen 1990: 179.

107 Cohen 1990: 179.

108 Cohen 1990: 184.
} 
conditions, containers would retain their integrity for hundreds of thousands of years. ${ }^{109}$ So the containers alone provide a rather complete protection system even if everything else fails. Thirdly the containers are surrounded by a backfill of clay that would swell if wet and form a tight seal keeping any water flow away from the package. ${ }^{110}$ The clay would also insulate the waste from minor earth movements. ${ }^{111}$ The fourth barrier is provided by placing the waste in a suitable geological environment or geosphere. Any waste which overcame the first three barriers would need to encounter conditions which would not provide opportunities to travel to the surface in groundwater. This means low rainfall to limit the means of transmission and a poor transport medium such as impervious rock with no fractures. It also means the depository being well above any water table which in turn would need to be long way from lower lying ground where it can come to the surface. The chosen sight would need to be in a region that was unlikely to be subject to future volcanic eruptions and it would have to be sufficiently deep so that neither meteorite impact nor surface erosion would expose the waste.

Cohen argues that virtually any deep ground storage would provide all the protection you would need in the totally unlikely event that the first three barriers were breached. ${ }^{112}$ He points out that even if exposed waste were surrounded by ground water it would take an extremely long time to reach the surface, if ever. Firstly, groundwater near the waste would take a thousand years or so to emerge because it moves very slowly and travels horizontally following the rock layers and hence typically must travel many miles before reaching surface land at a lower altitude. Secondly, the radioactive material will move far more slowly than the groundwater because it would constantly be filtered out by the rock material. Furthermore, it may well become a permanent part of the rock.

Finally, one needs to ask whether it would matter much if

\footnotetext{
109 Cohen 1990: 184.

110 Cohen 1990: 184.

111 Hore-Lacy 1999: 48.

112 Cohen 1990: 184.
} 
radiation from a particular location got into the food or water supply. If it was at a level that caused concern it would be quickly picked up by routine monitoring programs and fairly simple countermeasures could be taken such as refraining from growing crops, grazing animals or drinking the water. Furthermore, future advances in medical science will greatly reduce and possibly eliminate the threat posed by radiation. So, at some point radiation exposure may cease to be a health concern.

\section{Transporting Radioactive Waste}

The specter of radiation being released from nuclear waste while in transit is made much of by the radiophobes. The record to date, at least in the US has been incident free. Over the past 40 years the US industry has managed to move more than 3,000 shipments without a single radiological release. ${ }^{113}$

Certainly movements will increase considerably once centralized geological storage facilities are brought into operation and/or greater use is made of reprocessing plants. So any risk, if there is one, will increase. However, a serious radiation leak in transit is a very remote possibility. This is ensured by the tight regulations governing the activity, particularly concerning the form the waste must take and the method of containment.

The containers used are subject to tests to assess their ability to deal with a range of accidents or attacks. These include ensuring that they can withstand the effects of a high speed truck or train crash, burning jet fuel and the high pressures of deep water. Even if these containers were somehow breached, contamination would be greatly limited by the fact that the waste takes a solid form. It is unable to leak out like a liquid or a gas. Significant radiation exposure would be limited to people who chose to linger in the immediate vicinity of the accident. ${ }^{114}$

\section{Nuclear Terrorism}

There is a concern that having more nuclear power reactors

113 "Nuclear Energy Industry Salutes Senate for Approving Yucca

Mountain.” PR Newswire July 9, 2002.

114 Cohen 1990: 221. 
would increase the risk of terrorists getting their hands on the material required to make a nuclear weapon and so cause the level of death and misery achieved with the Hiroshima and Nagasaki bombs.

Achieving such a result would face a number of hurdles. Firstly, they would need to get together a small group of physicists, engineers, chemists, metallurgists and explosive specialists. They would not have to be experienced nuclear weapons makers but could rely on what is available in the open scientific literature. However, the more relevant their background the more smoothly the operation would proceed. There would then be the job of obtaining all the required equipment. Some of this would be difficult and in some cases would likely arouse suspicion

And finally there is the acquisition of the required nuclear material. Either highly enriched uranium or plutonium would fit the bill. Virtually all nuclear power reactors use only lightly enriched uranium and as long as plutonium produced in the fission process remains in the spent fuel, the level and type of radioactivity prevents it from being diverted to bomb making. Plutonium only exists separately where it is awaiting to be reprocessed into new fuel. This is carried out in Britain, France, India, Japan, and Russia, while the US at least up until now has opposed it because of proliferation concerns. Highly enriched uranium and plutonium are only used as a fuel in fast reactors. At the moment there are only a few in operation and a similar number are planned for China, India and Russia. Relatively large amounts of material would be required and any theft is unlikely to go unnoticed. The massive manhunt would mean that the time between the theft and the detonation would need to be fairly short.

The risk can be reduced in a number of ways. At the political level, the US is presently pursuing a course in the Middle East which should undermine the position of Jihad fascism, the main terrorist threat. At the time of writing, mainstream Islamists have already been brought into a democratic political process in Afghanistan, Iraq and Lebanon, with Egypt not far off. At the same time, the US induced Israeli withdrawal from the West Bank is now an inevitable event just waiting to hap- 
pen. At the regulatory level, it is a matter of ensuring that there is an adequate reviewing process which will detect any weaknesses in the internationally agreed arrangements for the storage and handling of nuclear material. New technologies can also play a role. For example, there is talk of reactors with tamper proof fuel which is returned to special facilities for storage, disposal or reprocessing.

\section{Concluding Comments on Nuclear}

Nuclear power could play an important although not dominant role in energy production during this century by simply relying on conventional uranium resources and moderate increases in the amount of energy extracted from each tonne of uranium. Playing a major role both in this time frame and in the longer term will depend on the adoption of new technologies such as breeder or thorium powered reactors and seawater extraction of uranium.

Given the health-giving qualities of economic growth and affluence, there is a limit to how much heed we should take of remote risks from nuclear power, if it otherwise makes economic sense. 


\section{ABBREVIATIONS}

$\mathrm{CO}$

$\mathrm{CO}_{2}$

DOE

EIA

EPA

EU

GDP

GtC

$\mathrm{H}$

IEA

IPCC

$\mathrm{kWh}$

LNTH

LWR

LWR

Mtoe

MW

NAS

$\mathrm{NO}_{x}$

OECD

OPEC

tcm

TMI

TWh

UN

UNSCEAR

WEC

WHO carbon monoxide

carbon dioxide

US Department of Energy

(US) Energy Information Administration

Environmental Protection Agency

European Union

gross domestic product

gigatonnes of carbon

hydrogen

International Energy Agency

International Panel on Climate Change

kilowatt hour

linear no threshold hypothesis

light water reactor

light water reactor

megatonnes oil equivalent

megawatt

National Academy of Sciences

nitrogen oxides

Organization for Cooperation and Development

Organization of Petroleum-Exporting Countries

trillion cubic meters

Three Mile Island

terawatt hour

United Nations

United Nations Scientific Committee on the Effects of Atomic Radiation

World Energy Council

World Health Organization 


\section{REFERENCES}

Abraham, Spence. 2002. Remarks Prepared for Delivery, Secretary of Energy Spence Abraham Global Nuclear Energy Summit The Cosmos Club Washington, D.C. February 14.

American Nuclear Society. 2001. Health Effects Of Low-Level Radiation. Position Statement 41. June.

Chen, W.L. et al. 2004. Is Chronic Radiation an Effective Prophylaxis Against Cancer? Journal of American Physicians and Surgeons.

Volume 9. Number 1. Spring.

Chernobyl Forum. 2003-2005. Chernobyl's Legacy: Health, Environmental and Socio-Economic Impacts and Recommendations to the Governments of Belarus, the Russian Federation and Ukraine. Second revised edition. Vienna: International Atomic Energy Agency.

Cohen, Bernard L. 1982. Exaggerating the Risk. In Kaku and Trainer (eds) 1982.

Cohen, Bernard L. 1990. The Nuclear Energy Option: An Alternative for the 90s. New York And London: Plenum Press.

Cohen, Bernard L. 1998. The Cancer Risk from Low Level Radiation. Radiation Research 149.

Daley, Michael J. 1997 Nuclear Power: Progress or Peril? Lerner Publications Company Minneapolis.

GAO. 2000. Report to the Honorable Pete Domenici, US Senate Radiation Standards, Scientific Basis Inconclusive, and EPA and NRC Disagreement Continues. United States General Accounting Office.

Garwin, Richard L. \& Georges Charpak. 2001. Megawatts and Megatons: a Turning Point in the Nuclear Age? New York. Alfred A. Knopf.

Grimston, Malcolm C. and Peter Beck. 2000. Civil nuclear energy : fuel of the future or relic of the past? London: Royal Institute of International Affairs, Energy and Environment Programme.

Hodgson, Peter E. 1999. Nuclear Power, Energy and the Environment. University of Oxford Imperial College Press.

Hoffman Jean M. 2001. Nuclear's New Age: New Nuclear Reactor Technology. Machine Design. September 27.

Holt, Mark. 2003. Civilian Nuclear Waste Disposal. Issue Brief for Congress. Congressional Research Service The Library of Congress. Resources, Science, and Industry Division. Updated January 29 2003. Order Code IB92059.

Hore-Lacy, Ian. 1999. Nuclear Electricity. 5th Edition.

Hore-Lacy, Ian. 2000. The Future of Nuclear Energy. Paper presented at the Royal College of Physicians Conference. Adelaide. 4th May. http://www.uic.com.au/opinion6.html

IEA. 2001b. Nuclear Power in the OECD. International Energy Agency. 
IEA. 2006a. Key World Energy Statistics 2005. International Energy Agency.

Kaku, Michio and Jennifer Trainer (eds). 1982. Nuclear Power, Both Sides: The Best Arguments For and Against the Most Controversial Technology. New York and London: W. W. Norton \& Company. Kursunoglu, Behram N., Stephan L. Mintz and Amold Perlmutter. 1998. Environment and Nuclear Energy. New York and London: University of Miami Coral Gables. Florida. Plenum Press.

NEA. 2001. Trends in the Nuclear Fuel Cycle: Economic, Environmental and Social Aspects. Nuclear Energy Agency. OECD.

NEA. 2004. Uranium 2003: Resources, Production and Demand. Nuclear Energy Agency. OECD.

Nero Jr, Anthony V. 1982. Safe Enough. In Kaku and Trainer (eds). 1982.

Oliver, Mike. 2001. Alternative Fuels? American Enterprise. September. Rutherford, Phil. 2002a. Radiation Risk: A Critical Look at Real and Perceived Risks from Radiation Exposure. Slide presentation. August 12, http://www.philrutherford.com/Radiation_Risk.pdf Rutherford, Phil. 2002b. Radiation Risk. http://www.philrutherford.com/Radiation_Risk_LNT.pdf Sims, Gordon. 1990. The Anti-Nuclear Game. University of Ottawa Press.

UIC. 2006a. Transport and the Hydrogen Economy. Nuclear Issues Briefing Paper \# 73. Uranium Information Centre. June. http://www.uic.com.au/nip73.htm

UIC. 2006b. Safety of Nuclear Power Reactors. Nuclear Issues Briefing \# 14. Uranium Information Centre. May. http://www.uic.com.au/nip14.htm van der Zwaan, B. C. C. et al. 1999. Nuclear Energy Promise or Peril? River Edge. NJ: World Scientific.

Walker J. Samuel. 2000. Permissible Dose: A History of Radiation Protection in the Twentieth Century. University of California Press Berkeley / Los Angeles / London

Wardell, Charles. 2001. The Politically Correct Nuke: MIT Students Help Design a Nuclear Power Plant that They Hope will Revive the Industry. Whole Earth. Winter. 
